\title{
Ergosterol analyses of oil palm seedlings and plants infected with Ganoderma
}

\author{
A.W. Mohd As'wad ${ }^{\text {a }}$, M. Sariah ${ }^{\text {a,* }}$, R.R.M. Paterson ${ }^{\text {c }}$, M.A. Zainal Abidin ${ }^{\text {b }}$, N. Lima ${ }^{\mathrm{c}}$ \\ ${ }^{a}$ Institute of Tropical Agriculture, Universiti Putra Malaysia, 43400 UPM Serdang, Selangor, Malaysia \\ ${ }^{\mathrm{b}}$ Department of Plant Protection, Faculty of Agricultuture, Universiti Putra Malaysia, 43400 UPM Serdang, Selangor, Malaysia \\ ${ }^{c}$ IBB Institute for Biotechnology and Bioengineering, Centre of Biological Engineering, Campus de Gualtar, University of Minho, 4710-057 Braga, Portugal
}

\section{A R T I C L E I N F O}

\section{Article history:}

Received 8 March 2011

Received in revised form

4 July 2011

Accepted 11 July 2011

\section{Keywords:}

Ganoderma boninense

Ergosterol

Oil palm

Diagnostic

\begin{abstract}
A B S T R A C T
Basal stem rot of oil palm (OP) by Ganoderma boninense is of major economic concern and it is the predominant disease of OP in SE Asia. Also, other plantation crops are affected by Ganoderma. The early detection of symptoms is crucial for control, although effective methods remain elusive. Ergosterol is the principal sterol of fungi and plays an essential role in the cell membrane and other cellular constituents. The analysis of ergosterol is useful for fungal detection in solid plant substrates. The present report compares ergosterol concentration in sound and decayed OP seedlings and mature plants using HPLC with diode array detection. The disease of OP requires to be considered as a white rot process where fungal biomass will increase from a low to high level as the infection progresses. G. boninense biomass was correlated with ergosterol concentration in vitro. Furthermore, the sterol was correlated with internal colonization (a) of inoculated seedlings, (b) of felled and standing OP and (c) to external symptoms of the disease. The compound was not detected in healthy samples. Disease treatments may be made more effective as the amounts of fungal biomass can be estimated and early detection is possible. Ergosterol quantification is a provisional diagnostic method for detection for G. boninense infection in OP which can be employed with other methods, enabling early remedial action to be taken. The method is recommended for further research involving basal stem rot of OP.
\end{abstract}

(c) 2011 Elsevier Ltd. All rights reserved.

\section{Introduction}

The major constraint to OP cultivation in Malaysian plantations is the incidence of Basal Stem Rot (BSR) disease caused by Ganoderma spp. A similar situation exists in many other countries (e.g. Indonesia) (Ariffin et al.,2000). Furthermore, species of Ganoderma are the causal agents of rots of numerous other plantation crops including coconut, rubber, betelnut, tea, cocoa, guarana, and grapevines. Forest trees such as Acacia, Populus and Macadamia are also affected.

The disease is a "white rot" process involving growth of the fungus within the OP as lignin and cellulose are biodegraded (Paterson, 2007a). Detection of BSR is based on the occurrence of unopened OP spear leaves and basidiomata of the fungus appearing on the trunks or primary roots near soil level. Confirmation is by the isolation, growth and identification of the fungus (Lim and Fong, 2005). This is time consuming and requires a high level of taxonomic expertise. The fungus is referred to as

\footnotetext{
* Corresponding author. Tel.: +60 38946 8967; fax: +60 386560698

E-mail address: sariahm@putra.upm.edu.my (M. Sariah).
}

Ganoderma boninense. At least half of the basal tissue will have been killed by the fungus by the time the foliar symptoms are observed (Ariffin et al.,2000) has been a recurrent theme of previous work.

Paterson (2007a) reviewed the literature on diagnostic methods for Ganoderma disease of OP. For example, six chapters in Flood et al. (2000) were devoted to diagnostic related information based on the molecular variability of Ganoderma spp. and the development of DNA methods. Paterson (2007b), Paterson et al. (2008) and Paterson and Lima (2009) reviewed PCR based techniques for Ganoderma disease of OP. The use of Enzyme-Linked Immunosorbent Assays-Polyclonal Antibody (ELISA-Pab) was reported (Utomo and Niepold, 2000). In addition, the development of (a) PODITOO ${ }^{\mathrm{TM}}$ tomography to locate and identify infection and (b) Geographical Information System (GIS) to detect possible sites and distribution of $G$. boninense infection in plantations have been attempted (Idris et al., 2009). Nevertheless, a robust, rapid and reliable early detection method is highly desirable with which to compliment these alternative methods.

Ergosterol is a cell membrane primary sterol specific to fungi (Axelsson et al., 1995) and which has been detected in other Ganoderma species (Paterson, 2006). The compound has been used 
to detect fungal invasion in grain and a variety of other substrates such as mycorrhizal roots, wood, foliage, soil and the aquatic environment (Salmanowicz and Nylund, 1988; Gao et al., 1993; Manter et al., 2001; Gong et al., 2001; Gessner and Newell, 2002 and Paterson, 2007c). Furthermore, the use of the sterol to detect growth of other white rot fungi (i.e. Hydnum and Polyporus) in sterilized OP in vitro was reported (Paterson et al.,2000), although the method has not been reported to estimate Ganoderma disease within OP. Treatments of Ganoderma disease would be made more effective if the amount of infection could be determined and early detection would permit culling of infected OP before the disease spread. Finally, ergosterol complements other methods such as PCR, for detecting plant disease (e.g. Yu et al., 2009).

In the present report, ergosterol was determined in (a) a G. boninense isolate from decayed $\mathrm{OP}$, (b) artificially inoculated oil palm seedlings (c) samples of sound and decayed OP stem removed previously from whole OP and (d) whole OP demonstrating disease symptoms in the field.

\section{Materials and methods}

\subsection{HPLC of ergosterol standard}

Ergosterol (>95\% HPLC pure, Sigma-Aldrich) standards were prepared in methanol and analyzed using reverse-phase HPLC (Supelco). The mobile phase was $100 \%$ methanol (HPLC grade) and the column used was an Ascentis express $2.7 \mu$ C18 reversephase. The flow rate of the mobile phase was $1.0 \mathrm{ml} \mathrm{min}^{-1}$ and the wavelength for the photodiode array detector (Waters Corp.) was $282 \mathrm{~nm}$. The ergosterol retention time was approximately $6.5 \mathrm{~min}$

\subsection{Ergosterol extraction}

The $G$. boninense isolate was from a basidiomata of an infected OP trunk which was growing in Banting, Selangor, Malaysia by using Ganoderma selective medium (Ariffin and Idris, 1991). The identification was confirmed by a resident plant pathologist, Universiti Putra Malaysia (UPM) and based on spore morphology and cultural characteristic. The pure culture was maintained on potato dextrose agar (PDA) (Merck) and preserved in an in-house culture collection at UPM. G. boninense pure cultures were cut to $0.5 \mathrm{~cm}^{2}$ and inoculated into unshaken $250 \mathrm{ml}$ Erlenmeyer flasks with $100 \mathrm{ml}$ Malt Extract Broth (MEB) (Merck) at ambient temperature $\left( \pm 25^{\circ} \mathrm{C}\right)$ to obtain the mycelium. After 3 weeks, mycelium was removed from the flask, rinsed with sterile distilled water and freeze-dried.

The non-alkaline ergosterol extraction (NAE) protocol used was based on that of Gong et al. (2001) with some modifications in the amount of the glass beads used and time of shaking with glass beads. Mycelium (100 mg) was added to $15 \mathrm{ml}$ polypropylene screw-cap centrifuge tube (Eppendorf) containing $2 \mathrm{~g}$ of acidwashed glass beads $(750 \mu \mathrm{m})$. After the addition of $6 \mathrm{ml}$ methanol, the vial was vortexed for $10 \mathrm{~s}$ and shaken intensively for 30 min on a bench-top orbital shaker (Protech) at room temperature, $20-25{ }^{\circ} \mathrm{C}$. The mycelium-methanol mixture was allowed to precipitate for $10 \mathrm{~min}$, and an aliquot of $1.0 \mathrm{ml}$ supernatant was transferred to a $1.5 \mathrm{ml}$ Eppendorf microtube. The microtube was centrifuged for $10 \mathrm{~min}$ at 11,000 oscillations $\mathrm{min}^{-1}$ in a Sigma Microcentrifugator. The supernatant $(1.0 \mathrm{ml})$ was filtered through a $0.2 \mu \mathrm{m}$ membrane syringe filter and the filtrate was placed in a $1 \mathrm{ml}$ sample tube that was loaded on an autosampler (Waters Corp.) for HPLC analysis.

\subsection{Ergosterol versus fungal biomass}

The freeze-dried mycelium was macerated using a mortar and pestle and liquid $\mathrm{N}_{2}$ until a powder was formed. Different mycelium masses $(0.1,0.5,1.0$ and $2.0 \mathrm{~g})$ in triplicate were extracted for ergosterol. The identification of ergosterol in all samples was achieved by comparing retention times and the diode array UV spectrum against the ergosterol standards.

\subsection{Oil palm seedlings}

Five month-old OP seedlings were used for the artificial infection study, consisting of two experimental variants (control (T1) and Ganoderma infected treatment (T2)). The OP seedlings used were commercial seedlings (Dura x Pisifera) supplied by Sime Darby Research Center at Banting, Selangor which were grown in a glasshouse until they reached the four to five leaf stage. The seedlings were uprooted carefully and transplanted into polybags (size $15 \mathrm{~cm} \times 23 \mathrm{~cm}$ ) containing $3 \mathrm{~kg}$ soil mixture $(3: 2: 1 \mathrm{v} / \mathrm{v} / \mathrm{v}$ topsoil: peat: sand). Treatments (T2) were inoculated with $G$. boninense colonized rubber wood blocks placed in contact with the roots (Sariah et al., 1994). Uninoculated seedlings were used as negative control. All OP seedlings were placed and arranged in complete randomized blocks under glasshouse conditions for 22 weeks. Destructive sampling of the seedlings was done over a period of 3, 6, 10, 14, 18 and 22 weeks to assess BSR infection. Random root samples ( $3 \mathrm{~g}$ ) were weighed and powdered finely with a mortar, pestle and liquid nitrogen. Samples were subjected to extraction followed by HPLC analysis. Ten inoculated and ten uninoculated seedlings were harvested for each sampling time. A visual assessment of BSR infection was determined by examining the roots of the seedlings and the severity of the symptoms expressed based on the proportion of lesioned (rotting) root.

\subsection{Oil palm sections}

Fifteen diseased and 3 healthy OP standing trunks were cut down with a chain saw from BSR-infected areas in the Malaysian Palm Oil Board (MPOB) Experimental Station Kluang, Johor. The palms were cut approximately $0.5-1 \mathrm{~m}$ from the base of the trunk and the BSR disease internal symptoms were observed by examining the cross section of cut OP stem tissue. The samples were classified visually from zero (healthy palm), low (yellow to light brown infected tissue), medium (brown infected tissue without fermented rancid odor) and high rot (extensive layer of dark brown infected tissue with strong fermented rancid odor). This is a standard method as described by Ariffin et al. (2000). The healthy and infected cut OP stem samples were slice into small blocks $(12 \mathrm{~cm} \times 12 \mathrm{~cm})$ with the chain saw and transported to the laboratory in an ice-chest and stored at $-20^{\circ} \mathrm{C}$. The block samples were ground using a Waring laboratory blender into a powder and tissue samples of $3 \mathrm{~g}$ were further ground using a mortar and pestle with liquid nitrogen to produce a fine powder. Samples were subjected to extraction followed by HPLC analysis.

\subsection{Standing oil palm}

Mature OP tissue samples were collected from high BSR disease incidence areas situated at Sime Darby Research Center, Banting, Selangor. The OP samples were chosen based on the appearances of external symptoms of BSR disease on the palm and were categorized into healthy, low infection and severe infection palms. Ten palms were sampled for each category. A Husqvarna 61 driller with drill size diameter $19 \mathrm{~mm}$ and length $15 \mathrm{~cm}$ (from MPOB) was used to penetrate the OP trunk to $8-20 \mathrm{~cm}$ of depth from four points 
(north, west, east and south). Each drill point was approximately $1 \mathrm{~m}$ from the base of the palm. A total of 15-20 g of tissue samples was collected and pooled from each palm and placed into a clean container, which was transported to the laboratory in an ice-chest and stored at $-20{ }^{\circ} \mathrm{C}$. Ergosterol was extracted using the NAE method. Tissue samples ( $3 \mathrm{~g}$ ) were weighed and powdered finely with a mortar, pestle and liquid nitrogen. Samples were subjected to extraction followed by HPLC analysis.

\subsection{Statistical analysis}

Statistical analysis was performed using SAS (version 9) software. The significant differences between means were determined using one-way analysis of variance (ANOVA) at 95\% confidence level. Products with the same letter have no significant difference with $P>0.05$. Correlation analysis was performed using Microsoft Excel 2007.

\section{Results}

The HPLC responses (peak area) were check for linearity within levels $(0.1-200 \mu \mathrm{g}$ ergosterol standard) for ergosterol standards. They were correlated with ergosterol concentrations and gave good correlation coefficients $\left(R^{2}\right)$ of 0.9982 . Ergosterol was detected from the $G$. boninense isolate and the concentration increased directly with the increase of biomass (Fig. 1). The lowest and highest mycelial biomass of $0.1 \mathrm{~g}$ and $2.0 \mathrm{~g}$ resulted in the lowest and highest ergosterol concentrations of $30.6 \mu \mathrm{g} \mathrm{g}^{-1}$ and $170.3 \mu \mathrm{g} \mathrm{g}^{-1}$ respectively.

The ergosterol concentrations increased significantly with the increase in the degree of root infection from 3, 6, 10, 14, 18 and 22 weeks after inoculation in the Ganoderma inoculated seedlings (Fig. 2). Ergosterol was absent in all uninoculated seedlings. The (a) highest concentration of ergosterol was $10.34 \mu \mathrm{g} / \mathrm{g}$ on week 22 with $>50 \%$ of root infection and (b) lowest concentration was $0.04 \mu \mathrm{g} / \mathrm{g}$ in week 3 with less than $10 \%$ infection of the roots infected. A good correlation $\left(R_{f}=0.959\right)$ was observed between the percentages of root infection and the ergosterol concentration after 3, 6, 10, 14, 18, and 22 weeks.

The sensitivity of ergosterol as a marker for detection of G. boninense in BSR-infected palms is indicated in Table 1 with respect to the OP section method. Ergosterol was detected in all infected OP samples (infected 1-15) and was absent in healthy samples (healthy 1-3). Ergosterol concentrations varied from each infected palms ranging from 0 to $50.0 \mu \mathrm{g} \mathrm{g}^{-1}$, which is equivalent to $0.01-0.20 \mathrm{~g} \mathrm{G}$. boninense $\mathrm{g}^{-1}$ OP tissue as deduced from the

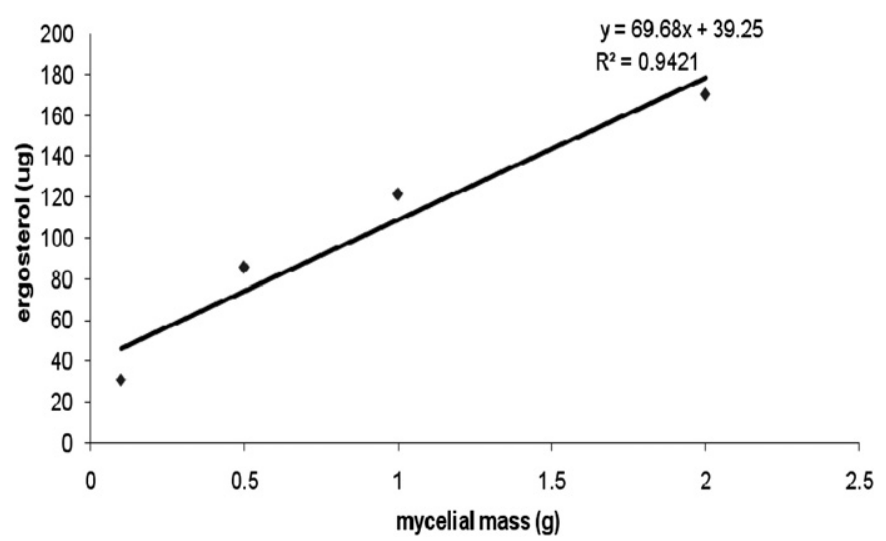

Fig. 1. Quantification of ergosterol in different weights of $G$. boninense mycelia. Data represent means and standard deviation of three replicated samples.

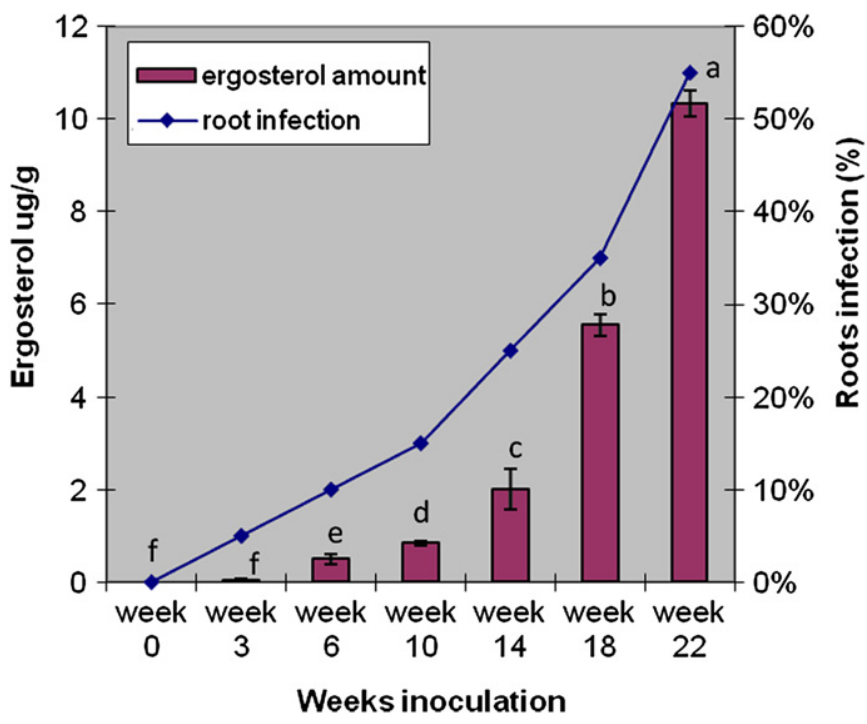

Fig. 2. Ergosterol concentration and root infection percentage in inoculated seedlings. Bars represent means \pm SD (error bar) of 10 replicated samples. Significant different for each disease level indicated by different letters $(P<0.05$, ANOVA).

standard curve. The average ergosterol concentrations for healthy, low, medium and highly-infected OP were $0.00,3.90,16.11$, and $29.72 \mu \mathrm{g} \mathrm{g}^{-1}$ OP respectively (Fig. 3 ).

Ergosterol was detected in all infected OP samples using the standing OP method and absent in all healthy palm samples. Ergosterol concentration varied from (a) slightly-infected palms (low infection 1-10) with concentrations from 0.85 to $5.02 \mu \mathrm{g} \mathrm{g}^{-1}$ OP tissue to (b) severe infection samples $1-10$ with concentrations from 17.27 to $42.56 \mu \mathrm{g} \mathrm{g}^{-1}$ OP tissue. The relationship of ergosterol concentration with external symptoms of BSR is indicated in Table 2. The mean ergosterol concentrations for healthy, low and severely-infected OP were $0.00,2.56$, and $26.22 \mu \mathrm{g} \mathrm{g}^{-1}$ OP respectively (Fig. 4).

Table 1

Relationship between ergosterol concentration and organoleptic assessment (OA) of disease severity from infected oil palm section samples. Ergosterol data represent standard deviation of three samples per palm.

\begin{tabular}{|c|c|c|}
\hline Oil Palm & ${ }^{\mathrm{a} O A}$ of BSR disease severity & Ergosterol concentration (ug/g) \\
\hline Healthy 1 & 0 & not detected \\
\hline Healthy 2 & 0 & not detected \\
\hline Healthy 3 & 0 & not detected \\
\hline Infected 1 & Low & $0.93 \pm 0.16$ \\
\hline Infected 2 & Low & $2.32 \pm 0.14$ \\
\hline Infected 3 & Low & $4.34 \pm 0.24$ \\
\hline Infected 4 & Low & $4.66 \pm 0.16$ \\
\hline Infected 5 & Low & $7.27 \pm 0.19$ \\
\hline Mean & & $3.90 \pm 2.42$ \\
\hline Infected 6 & Medium & $15.74 \pm 0.23$ \\
\hline Infected 7 & Medium & $15.34 \pm 0.23$ \\
\hline Infected 8 & Medium & $17.24 \pm 0.26$ \\
\hline Mean & & $16.11 \pm 1.00$ \\
\hline Infected 9 & High & $17.33 \pm 0.24$ \\
\hline Infected 10 & High & $18.45 \pm 0.13$ \\
\hline Infected 11 & High & $23.56 \pm 0.25$ \\
\hline Infected 12 & High & $23.85 \pm 0.19$ \\
\hline Infected 13 & High & $37.60 \pm 0.23$ \\
\hline Infected 14 & High & $38.65 \pm 0.41$ \\
\hline Infected 15 & High & $48.60 \pm 0.34$ \\
\hline Mean & & $29.72 \pm 11.91$ \\
\hline
\end{tabular}

low-Yellow to light brown infected tissue medium-Brown infected tissue without fermented rancid odor high-Extensive layer of dark brown infected tissue with strong fermented rancid odor.

a Disease severity score. 


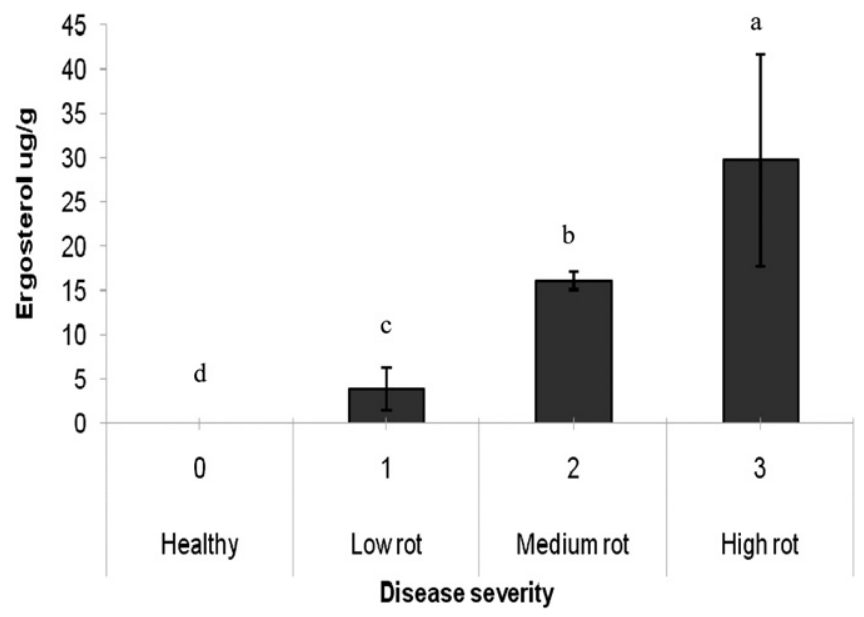

Fig. 3. Mean ergosterol ( $\mu \mathrm{g} \mathrm{g}^{-1}$ OP tissue) compared to degree of rot of oil palm sections. $(0=$ healthy tissue; $1=$ low rot as assessed by a yellow to light brown infected tissue; 2 = medium rot as assessed by brown infected tissue without a fermented rancid odor; 3 = high rot as assessed by an extensive layer of dark brown infected tissue with a strong fermented rancid odor). Bars represent means $\pm \mathrm{SD}$ (error bar) of three samples per palm. Significant different for each disease severity indicated by different letters $(P<0.05$, ANOVA). (For interpretation of the references to color in this figure legend, the reader is referred to the web version of this article.)

\section{Discussion}

The present paper represents the first report for detection of ergosterol from $G$. boninense, although the compound has been detected from other species of Ganoderma (Paterson, 2006). The current work demonstrates uniquely that the sterol can be employed to quantify and detect the BSR symptoms in OP. Paterson et al. (2000) had established that ergosterol could be employed to measure growth of Hydnum and Polyporus in an in vitro system using OP blocks.

The relationship between ergosterol concentration and G. boninense mycelial biomass indicated that ergosterol increased proportionally to biomass. Similar findings also have been reported from other fungi (Paterson et al.,2000; Manter et al., 2001; $\mathrm{Ng}$ et al. 2007; Paterson 2007c). These findings suggested that ergosterol related directly to the growth and severity of $G$. boninense infection in OP grown in plantations. Artificially inoculated seedlings demonstrated an increase in ergosterol concentration with greater root infection over time but it was not detected in uninoculated seedlings. This further indicated the effectiveness of ergosterol for monitoring G. boninense infection. Furthermore, ergosterol was not detected in healthy palms, while it was present in all infected OP samples and the concentration varied proportionately to the degree of infection. A direct relationship between internal symptoms and ergosterol concentrations was demonstrated. Furthermore, ergosterol concentration was related directly with the external symptoms of BSR and indicated that the method is suitable for direct sampling in the field.

It may be worth pointing out that it is extremely difficult to undertake numerous repeats within the same sets of experiments as might be possible on other crops, due to the nature of the host. $\mathrm{OP}$ is very slow growing and normally takes 20 years to reach maturity. We compensated for this limitation by using 15 palms per analysis which is a high level of repetitions for OP-related experimentation.

Ergosterol is a robust method for detection for $G$. boninense infection in oil palm. The fungal metabolite is absent from vascular plants and most other organisms, although it may be present in a minor amounts, in bacteria, cyanobacteria, green and microalgae and protozoa (Gessner and Newell, 2002). In addition, plants produce different sterols such as sitosterol and phytosterols which
Table 2

Relationship between ergosterol concentration and external symptoms assessment of disease severity from infected standing oil palm stem samples. Ergosterol data represent standard deviation of three samples per palm.

\begin{tabular}{ll}
\hline Samples $^{\mathrm{a}}$ & Ergosterol concentration $^{\mathrm{b}}$ \\
\hline Healthy & \\
1 & $\mathrm{ND}^{\mathrm{c}}$ \\
2 & $\mathrm{ND}$ \\
3 & $\mathrm{ND}$ \\
4 & $\mathrm{ND}$ \\
5 & $\mathrm{ND}$ \\
6 & $\mathrm{ND}$ \\
7 & $\mathrm{ND}$ \\
8 & $\mathrm{ND}$ \\
9 & $\mathrm{ND}$ \\
10 & $\mathrm{ND}$ \\
Mean & ND
\end{tabular}

$\begin{array}{ll}\text { Low } & 2.32 \pm 0.34 \\ 1 & 4.58 \pm 0.30 \\ 2 & 3.93 \pm 0.14 \\ 3 & 0.93 \pm 0.16 \\ 4 & 2.52 \pm 0.24 \\ 5 & 0.85 \pm 0.18 \\ 6 & 5.02 \pm 0.16 \\ 7 & 1.53 \pm 0.26 \\ 8 & 1.10 \pm 0.17 \\ 9 & 2.85 \pm 0.18 \\ 10 & \mathbf{2 . 5 6} \pm \mathbf{1 . 5 2}\end{array}$

\begin{tabular}{ll} 
Severe & $17.27 \pm 0.20$ \\
1 & $24.66 \pm 0.18$ \\
2 & $18.33 \pm 0.21$ \\
3 & $25.34 \pm 0.17$ \\
4 & $23.85 \pm 0.18$ \\
5 & $27.24 \pm 0.31$ \\
6 & $24.74 \pm 0.25$ \\
7 & $19.56 \pm 0.17$ \\
8 & $38.65 \pm 0.41$ \\
9 & $42.56 \pm 0.22$ \\
10 & $\mathbf{2 6 . 2 2} \pm \mathbf{8 . 3 0}$ \\
\hline
\end{tabular}

a Samples (disease severity score). Low-appearance of foliar symptoms (1-2 unopened spear leaves). Severe-appearance severe foliar symptoms with or without appearance of fruiting body.

b Ergosterol data represent mean and standard deviation of three samples per palm.

c $\mathrm{ND}=$ no data.

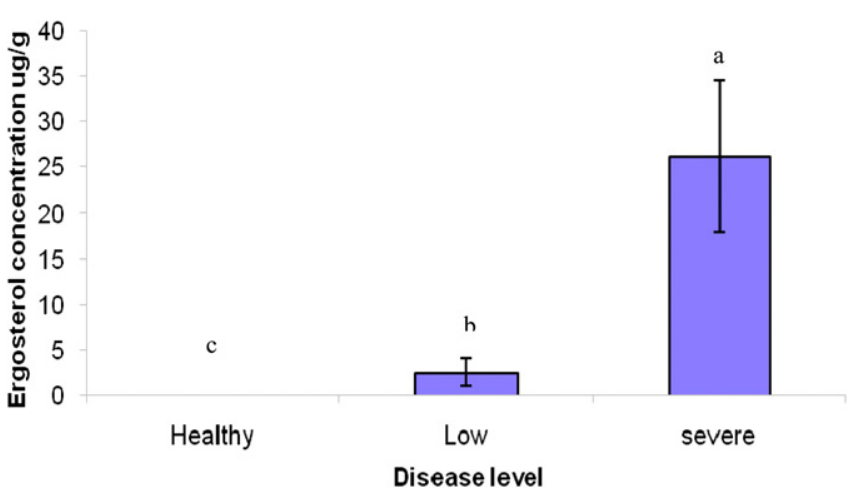

Fig. 4. Mean ergosterol ( $\mu \mathrm{g} \mathrm{g}^{-1}$ OP tissue) compared to degree of BSR external symptom in standing oil palm. (Healthy = healthy palms; Low = low infection assessed by appearance of foliar symptoms (1-2 unopened spear leaves); Severe = severe infection assessed by severe foliar symptoms with or without appearance of fruiting body). Bars represent means \pm SD (error bar) of three samples per palm. Significant different for each disease level indicated by different letters $(P<0.05$, ANOVA). 
are not produced in fungi (Weete, 1974). These results demonstrate that ergosterol concentration can be used to assess the growth of the fungus within the palm and may be useful for root, foliar and other samples (Salmanowicz and Nylund, 1988; Manter et al., 2001; Gong et al., 2001).

In conclusion, the results from our studies support the view that ergosterol is a diagnostic method with utility for the detection of BSR in oil palm. This represents the first data published on the use of ergosterol analysis as a diagnostic method to detect BSR and indicates a new direction of research in BSR management.

\section{Acknowledgements}

The authors wished to thank the Malaysian Palm Oil Board (MPOB) for the supply of materials in this research and Universiti Putra Malaysia (UPM) under the Fundamental Research Grant Scheme for the research grant received. R.R.M. Paterson gratefully appreciates obtaining the IOI Professorial Chair, Department of Plant Protection, Universiti Putra Malaysia, Malaysia under which this work was initiated, and for the FCT framework position: Commitment to Science ref. C2008-UMIN-HO-CEB-2.

\section{References}

Ariffin, D., Idris, A.S., 1991. A selective medium for the isolation of Ganoderma from diseased tissues. 9-14 September 1991. In: Yusof, et al. (Eds.), Proceedings of the International Palm Oil Conference, Progress, Prospects and Challenges Towards the 21st Century (Model I, Agriculture). Palm Oil Research Institute of Malaysia, Malaysia, pp. 517-519.

Ariffin, D., Idris, A.S., Singh, G., 2000. Status of Ganoderma in oil palm. In: Flood, J., Bridge, P.D., Holderness, M. (Eds.), Ganoderma Diseases of Perennial Crops. CABI Publishing, Wallingford, pp. 49-68.

Axelsson, B.-O., Saraf, A., Larsson, L., 1995. Determination of ergosterol in organic dust by gas chromatography-mass spectrometry. J. Chromatogr. B. 666, 77-84.

Flood, J., Bridge, P.D., Holderness, M. (Eds.), 2000. Ganoderma Diseases of Perennial Crops. CABI Publishing, Wallingford.

Gao, Y., Chen, T., Breuil, C., 1993. Ergosterol- a measure of fungal growth in wood for staining and pitch control fungi. Biotechnol. Tech. 7, 621-626.

Gessner, M.O., Newell, S.Y., 2002. Biomass, growth rate, and production of filamentous fungi in plant litter. In: Hurst, C.J., Crawford, R.L., Knudsen, G.,
Mclnerney, M, Stetzenbach, L.D., Stetzenbach, L.D. (Eds.), Manual of Environmental Microbiology, second ed. ASM Press, Washington, DC, pp. 390-408.

Gong, P., Guan, X., Witter, E., 2001. A rapid method to extract ergosterol from soil by physical disruption. Appl. Soil Ecol. 17, 285-289.

Idris, A.S., Mazliham, M.S., Madihah, A.Z., 2009. Current technologies for detection of Ganoderma in oil palm. In: (Unedited) Proceedings of Agriculture, Biotechnology and Sustainability Conference. PIPOC, Kuala Lumpur, pp. 81-99.

Lim, H.P., Fong, Y.K., 2005. Research on basal stem rot (BSR) of ornamental palms caused by basidiospores from Ganoderma boninense. Mycopathologia 159, $171-179$.

Manter, D.K., Kelsey, R.G., Stone, J.K., 2001. Quantification of Phaeocryptopus gaeumannii colonization in Douglas- ${ }^{\circledR} \mathrm{r}$ needles by ergosterol analysis. For. Pathol. 31 229-240.

Ng, H.-E., Raj, S.S.A., Wong, S.H., Tey, D., Tan, H.-M., 2007. Estimation of fungal growth using the ergosterol assay: a rapid tool in assessing the microbiological status of grains and feeds. Lett. Appl. Microbiol. 46, 113-118.

Paterson, R.R.M., Holderness, M., Kelley, J., Miller, R.N.G., O’Grady, E., 2000. In vitro biodegradation of oil palm stem using macroscopic fungi from South East Asia:a preliminiary investigation. In: Flood, J., Bridge, P.D., Holderness, M. (Eds.) Ganoderma Diseases of Perennial Crops. CABI Publishing, Wallingford, pp. 129-139.

Paterson, R.R.M., 2006. Ganoderma-a therapeutic fungal biofactory. Phytochemistry 67, 1985-2001.

Paterson, R.R.M., 2007a. Ganoderma disease of oil palm- a white rot perspective necessary for integrated control. Crop Prot. 26, 1369-1376.

Paterson, R.R.M., 2007b. Internal amplification controls have not been employed in diagnostic fungal PCR hence potential false negative results. J. Appl. Microbiol. 102, 1-10.

Paterson, R.R.M., 2007c. Zearalenone production and growth in drinking water inoculated with Fusarium graminearum. Mycol. Prog. 6, 109-113.

Paterson, R.R.M., Sariah, M., Lima, N., Zainal Abidin, M.A., Santos, C., 2008. Mutagenic and inhibitory compounds produced by fungi affect detrimentally diagnosis and phylogenetic analyses. Curr. Bioact Compd 4, 245-257.

Paterson, R.R.M., Lima, N., 2009. Mutagens manufactured in fungal culture may affect DNA/RNA of producing fungi. J. Appl. Microbiol. 106, 1070-1080.

Salmanowicz, B., Nylund, J.E., 1988. High performance liquid chromatography determination of ergosterol as a measure of ectomycorrhiza infection in Scots pine. Eur. J. For. Pathol. 18, 291-298.

Sariah, M., Zakaria, M.H., Miller, R.N.G., Holderness, M., 1994. Pathogenecity of Ganoderma boninense tested by inoculation of oil palm seedlings. Plant Path 43 507-510.

Utomo, C., Niepold, F., 2000. The development of diagnostic tools for Ganoderma in oil palm. In: Flood, J., Bridge, P.D., Holderness, M. (Eds.), Ganoderma Diseases of Perennial Crops. CABI Publishing, Wallingford, pp. 235-248.

Weete, J.D., 1974. Fungal Lipid Biochemistry. Plenum Press, New York.

Yu, M., Hodgetts, J., Rossall, S., Dickinson, M., 2009. Using terminal restriction fragment length polymorphism (t-rflp) to monitor changes in fungal populations associated with plants. Plant Path 91 (2), 417-423. 